I have only met with the condition in bitches, but an excellent description of it as affecting dogs will be found in the abovementioned article by Smith and Washbourne.

When a bitch is brought for inspection the history usually is that "she cannot be got to breed." Examination of the vagina reveals the presence of the new growths; these are generally single, but in some cases multiple, about the consistency of a lymphatic gland, more or less cauliflower-shaped, varying in size from a pea up to a walnut, covered externally with mucous membrane, and attached in most cases to the floor of the vagina near the urethral orifice. By careful manipulation one can frequently pull the tumour outside the vulva for inspection. It usually bleeds on manipulation unless very gently handled. In an old or aggravated case the whole circumference of the vaginal mucous membrane may be covered with a dense lobulated mass of the new growth, which may reach the size of a large apple and cause the vulva to bulge considerably behind. I have one such case under observation at present.

Microscopic examination shows that the tumours are composed of round cells, and Smith and Washbourne regarded them as roundcelled sarcomata, a class of tumours which is recognised as being particularly malignant, and in this case we might add contagious. ${ }^{1}$

The only satisfactory method of treatment is complete excision, taking great care to leave no portion behind, as the least bit appears to be sufficient to determine a recurrence. In those cases where there is sufficient pedicle, a wire ecraseur answers the purpose quite well, but in others, where there is no appreciable pedicle, a speculum, bistoury, and curved scissors will be required. The wounds usually heal well and require no special treatment. No prophylactic measure short of refusing service of an affected animal seems to be of any use. The most careful disinfection of the affected organs after copulation cannot be relied on as a preventive.

\title{
CASES OF NICOTINE AND BELLADONNA POISONING IN THE DOG.
}

\author{
By G. H. Lrvesey, M.R.C.V.S., Hove.
}

A FEW evenings ago I was called out to see a dog supposed to be dying in a fit. The dog, a large fox-terrier, was in a darkened room with a wet cloth round his head. The dog was well nourished and in good condition, but its muscles were all in a state of clonic spasm, especially the masseters and those of the neck and abdomen. The membrana nictitans almost entirely obscured the eyes, which were very much retracted within the orbits. He had been in this condition for about an hour before I saw him. On making a closer examination I found the mouth to be very moist, the mucous membranes rather pale with a bluish tinge, the pulse quick and full, the respiration deeper, but not so fast as I should have expected from the condition of the pulse. The extremities were cold and the skin ténse, and the nose cold but dry. Deglutition was apparently impossible.

I [The classification of these growths with the sarcomata is not justifiable, in view of the fact that they represent the lesions of an infective disease, and have a histology closely resembling that of granulation tissue. $-J$. M ' F.] 
The history of the case at first did not help me very much. The dog "had not been himself" for four or five days, had been very much troubled with worms, and "had passed masses of them every day." I have seen hundreds of dogs with epileptiform fits, or with the fits which are nearly always ascribed to worms in the stomach or bowel, but this condition was quite new to me, and I hesitated to make a diagnosis. Meanwhile I gave the $\operatorname{dog}$ bromide of potassium in a tabloid, as he could not voluntarily swallow, and I had no means at hand for giving the drug per rectum, where I doubt if it would have been retained.

I feared the dog had been poisoned, but on that head could gain no information from the owner for a long time. At length, by judicious cross-questioning, I found out that the dog had been sick before the convulsions came on, so at once inspected the vomit. Here, amongst other matter, I was surprised to find a lump, amounting to about half ounce, of plug tobacco. On my pointing this out, I readily obtained all the information I wanted. The owner, strongly advised by some very "doggy" friends, had given the tobacco about 8 P.M. to get rid of the worms and "get a passage through him." About 20 minutes after the dose the dog had tried to defecate, and had strained violently but without success, much to his owner's disappointment. During the period of straining the dog had fallen over in convulsions. His owner thought (to use his own words) "he had strained his heart or his guts," and so had sent for me, as they were sure he was dying, and did not feel equal to tackling such a case.

The dog was now quieter but showing signs of collapse-the body cold, respiration shallow, the heart very slow and feeble. He had quite lost the use of his legs, which hung limp and paralysed when he was lifted up. The limbs, however, were occasionally slightly convulsed, while the muscles of the right shoulder showed a persistent tremor.

I had no apomorphine with me, which I much regretted, as I judged this to be a most suitable case for its use. I gave strychnine, and obtained a good reaction, the heart responding well. The convulsions ceased, after lasting for just over five hours. As soon as he could swallow he had some diluted alcohol, when he was sick again, the vomit being stained brown, smelling of tobacco, and mixed with a small amount of blood. I left him wrapped up warmly and fairly comfortable.

The next day he seemed practically well again, and ate some raw meat from my hand, and I have not seen him since.

Since visiting the $\operatorname{dog}$ I have looked up some of the literature on nicotine poisoning, and find it compared to that by belladonna. A case of belladonna poisoning recently came under my notice in which a fox-terrier bitch had licked herself after being freely rubbed with the B. P. liniment. In this case the symptoms 'came on gradually; the bitch first appeared to be going blind, stumbling over small objects in her path. She walked slowly, with difficulty. and tended to move in a circle, finally staggering and falling with complete loss of muscular power in her hind legs only. There were no convulsions, but persistent grinding of the teeth; pulse and respirations greatly accelerated. The symptoms gradually subsided, and passed off in about four hours after the administration of small quantities of brandy in 
warm milk. The pupil was not dilated as one would have been led to expect. In fact, it was if anything contracted.

In the above case of nicotine poisoning the condition of the eyes was peculiar. The globe was so retracted that the membrana nictitans obscured the cornea, and only an imperfect view of the iris could be obtained. So far as I could judge, the left pupil was slightly, and the right pupil distinctly, contracted. In writing of nicotine poisoning in human beings, Hale White says the pupil is contracted by sympathetic paralysis and irritation of the 3 rd nerve. Dr Thomas Stevenson, the poison expert, states that the pupil is widely dilated.

If one were in any doubt, however, as to which of the two poisons is in the system, conclusive evidence should be afforded by the mouth. which in the case of belladonna would be dry or gummy, whereas in the case of nicotine poisoning the mouth would be moist, or even contain a quantity of saliva and mucus, and probably smell of the tobacco.

\section{A DIFFICULT DIAGNOSIS.}

By Robt. G. Anderson, M.R.C.V.S., Wellington, Somerset.

ON 12th March last a six-years-old Devon cow in full milk was seen by its owner to be unwell, and it was attended by me on the same day. Temperature $106^{\circ}$, pulse frequent but regular and of good volume. A cause for this fevered state seemed to exist in an inflammatory condition, evidenced by a marked dulness, but without pleuritic sounds, at the base of the right lung. A marked grunt suggested an implication of the liver and second or third stomach. Without previous history of indigestion, a foreign body was not suspected.

Treatment here, as throughout the duration of the case, was directed solely to the alleviation of marked symptoms.

A previous experience of redwater in a similar animal caused the owner to be on the look-out for its symptom, and on the second day he had noticed a flow of distinctly coloured urine. This symptom disappeared in a few days under specific treatment.

At this time the condition of the lung had improved, the grunt was also gone, but the temperature remained high. Auscultation to discover if any fresh portion of lung had become invaded, seemed to find it high up on the left side, but more particular attention showed the vesicular murmur to be of its normal softness, with slightly increased frequency, and the quite marked roughness to proceed from the tissues external to the ribs. Indeed, a movement of the ear over the part, and further manipulation of it, made out an emphysematous condition of the subcutaneous tissues. This was also to be distinctly felt over the loins. It was thought possible that this condition was due to a puncture of lung or windpipe, but its probability was doubted, and indeed eventually dismissed. In a district where quarter-evil is well known this symptom is taken as decisive of its existence, but the age of the animal and the length of time that it had lived after showing this symptom were difficult to get over.

To end what seemed to be a very uncertain case, and solve the mystery of its causation, slaughter was advised. A second opinion was first had, and this being to the effect that the condition was 